\title{
Patient with Anaphylaxis Following Blunt Abdominal Trauma
}

\author{
Kamil Kokulu (D), Can Ozen (D), Hayrullah Yonak (D) \\ Department of Emergency Medicine, Health Sciences University Umraniye Training and Research Hospital, Istanbul, Turkey
}

Cite this article as: Kokulu K, Ozen C, Yonak H. Patient with Anaphylaxis Following Blunt Abdominal Trauma. Eurasian J Emerg Med. 2018; 17 (4): 207-8.

A previously healthy 22-year-old man presented to the emergency department with abdominal pain, nonbloody and nonbilious vomiting, flushing, and a syncopal episode following a minor blunt abdominal trauma. The patient denied any history of allergic reaction and drug usage. His temperature was $36.3^{\circ} \mathrm{C}$, pulse was 127 beats/ minute, and blood pressure was $95 / 52 \mathrm{mmHg}$. Physical examination revealed tenderness of the epigastric region and the upper right quadrant, with diffuse flushing of the skin. White blood cell counts, hemoglobin and hematocrit levels, and liver functions were found to be normal. Laboratory studies demonstrated elevated arterial-

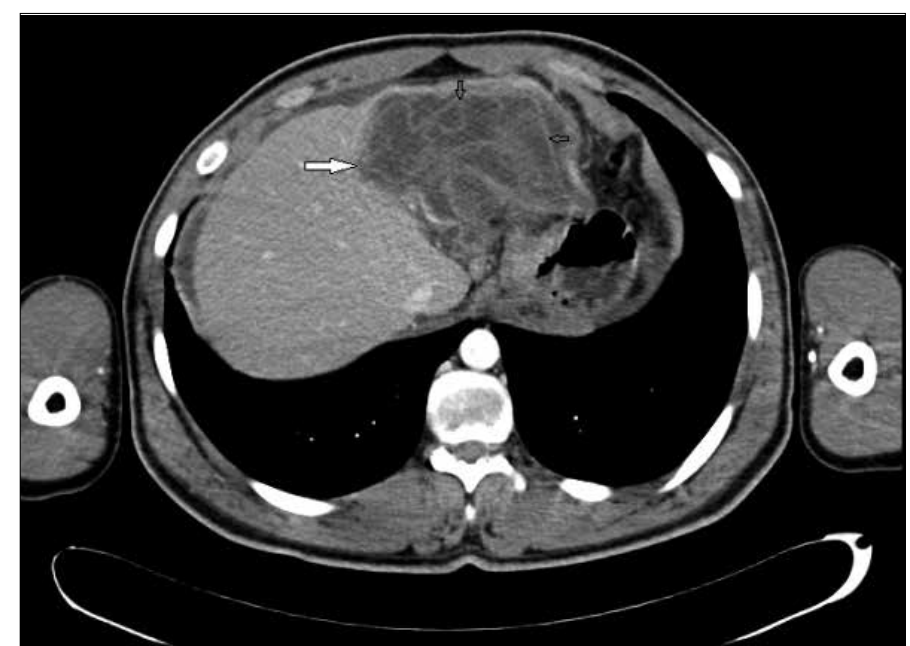

Figure 1. Abdominal computed tomography with intravenous contrast (axial view) showing a partially collapsed cystic lesion (white arrow) with a diameter of $11 \mathrm{~cm}$ at its widest portion, losing its normal spherical shape, having a lobulated margin, and containing a number of septations (red arrows) within

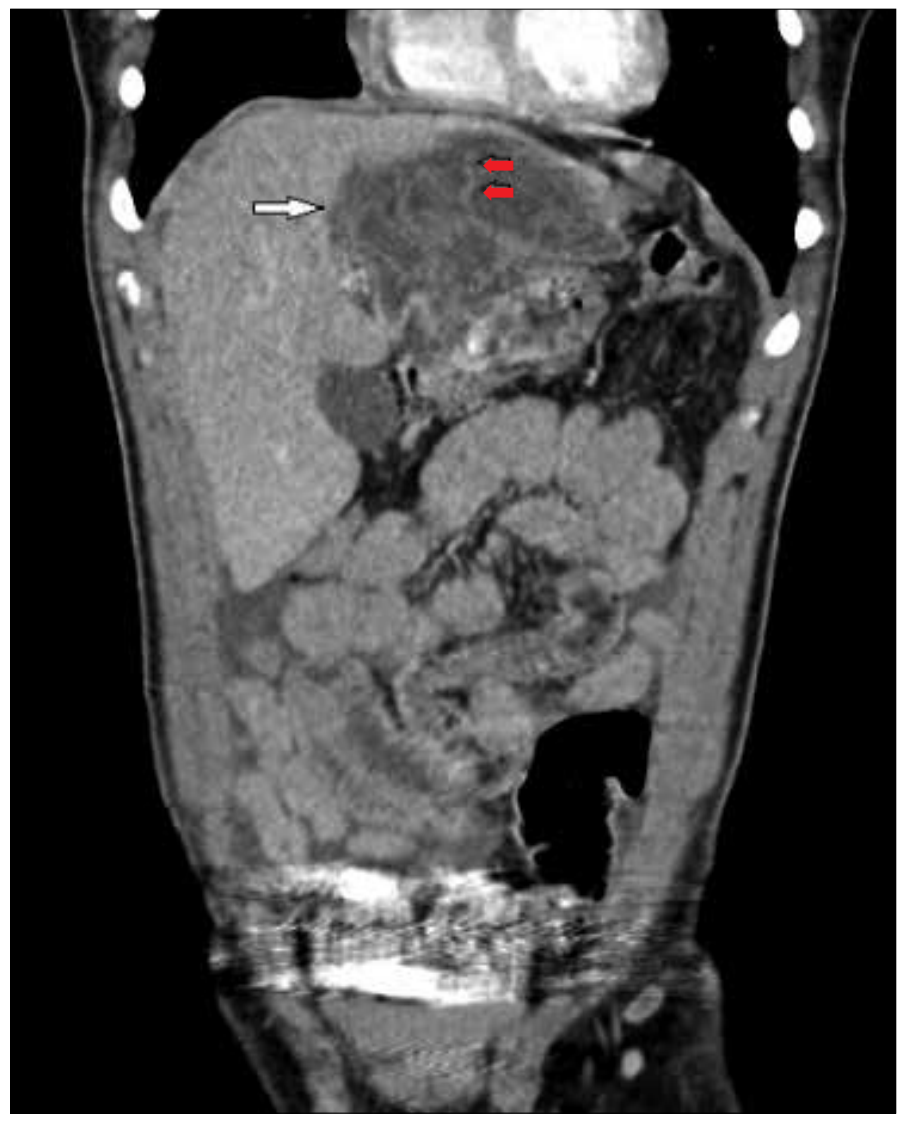

Figure 2. Abdominal computed tomography with intravenous contrast (coronal view) showing a partially collapsed cystic lesion (white arrow), losing its normal spherical shape, having a lobulated margin, and containing a number of septations (red arrows) within

ORCID IDs of the authors: K.K. 0000-0002-6132-0898; C.O. 0000-0003-2691-847X; H.Y. 0000-0001-8057-540X. 


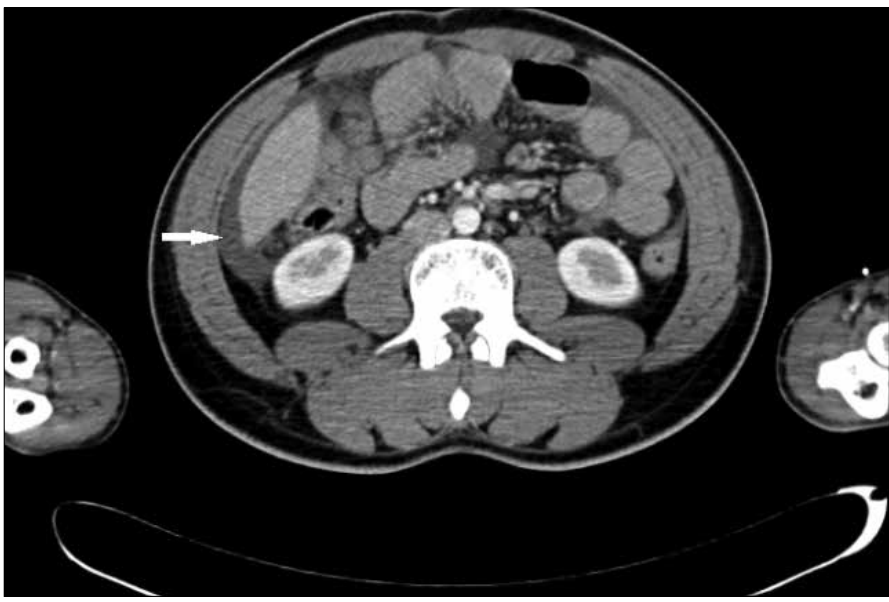

Figure 3. Abdominal computed tomography with intravenous contrast (axial view) showing free fluid (arrow) in the perihepatic region.

lood lactate level of $3.3 \mathrm{mmol} / \mathrm{L}$ (reference range, 0.5-1.6 mmol/L). Focused assessment with sonography in trauma revealed free fluid in all abdominal quadrants. Contrast-enhanced computed tomography of the abdomen was performed because the diagnosis was not clear (Figures 1-3).

The patient was diagnosed with acute anaphylaxis due to a ruptured hydatid cyst of the liver. Hydatid cyst is a parasitic disease caused by four distinct Echinococcus species (E. granulosus, E. multilocularis, E. vogeli, and E. oligarthrus) (1). Humans are infected through the ingestion of parasite eggs, which are released in the stool of infected canines $(2,3)$. The most common presentation is hydatid cyst with liver localization (1). Hydatid cyst rupture due to strenuous physical activity, abdominal trauma, or surgical trauma is a well-known etiology of anaphylaxis $(2,4)$. If a hydatid cyst ruptures, release of cystic content can result in allergic reactions ranging from a mild allergic reaction to anaphylaxis (1).
The patient was treated with fluid resuscitation, diphenhydramine, nasal oxygen, and glucocorticoids and operated thereafter. Albendazole was prescribed following the surgery. The patient was discharged home with cure on the $7^{\text {th }}$ day of admission. Informed consent was obtained from the patient who participated in this case.

Informed Consent: Written informed consent was obtained from patient who participated in this study.

Peer-review: Externally peer-reviewed.

Author Contributions: Concept - K.K.; Design - K.K., C.O.; Supervision K.K., H.Y.; Resources - K.K., C.O.; Materials - K.K., H.Y.; Data Collection and/or Processing - K.K., H.Y.; Analysis and/or Interpretation - K.K.; Literature Search - K.K., C.O.; Writing Manuscript - K.K.; Critical Review - K.K., C.O.

Conflict of Interest: The authors have no conflict of interest to declare.

Financial Disclosure: The authors declared that this study has received no financial support.

\section{References}

1. Moro P, Schantz PM. Echinococcosis: A review. Int J Infect Dis 2009; 13: 125-33. [CrossRef]

2. Li Y, Zheng H, Cao X, Liu Z, Chen L. Demographic and clinical characteristics of patients with anaphylactic shock after surgery for cystic echinococcosis. Am J Trop Med Hyg. 2011; 85: 452-5. [CrossRef]

3. Murali MR, Uyeda JW, Tingpej B. Case records of the Massachusetts General Hospital. Case 2-2015. A 25-year-old man with abdominal pain, syncope, and hypotension. N Engl J Med. 2015; 372: 265-73. [CrossRef]

4. Jedidi M, Mlayeh S, Masmoudi T, Souguir MK, Zemni M. Sudden death due to hydatid cyst: thirty-four medicolegal autopsy cases. Am J Forensic Med Pathol. 2014; 35: 29-33. [CrossRef] 